\title{
Effect of spatial differences in growth on distribution of seasonally co-occurring herring Clupea harengus stocks
}

\author{
Worsøe Clausen, Lotte; Stæhr, Karl-Johan; Rindorf, Anna; Mosegaard, Henrik
}

Published in:

Journal of Fish Biology

Link to article, DOI:

$10.1111 / \mathrm{jfb} .12571$

Publication date:

2015

Document Version

Peer reviewed version

Link back to DTU Orbit

Citation (APA):

Worsøe Clausen, L., Stæhr, K-J., Rindorf, A., \& Mosegaard, H. (2015). Effect of spatial differences in growth on distribution of seasonally co-occurring herring Clupea harengus stocks. Journal of Fish Biology, 86(1), 228-247. https://doi.org/10.1111/jfb.12571

\section{General rights}

Copyright and moral rights for the publications made accessible in the public portal are retained by the authors and/or other copyright owners and it is a condition of accessing publications that users recognise and abide by the legal requirements associated with these rights.

- Users may download and print one copy of any publication from the public portal for the purpose of private study or research.

- You may not further distribute the material or use it for any profit-making activity or commercial gain

- You may freely distribute the URL identifying the publication in the public portal 


\section{Effect of spatial differences in growth on distribution of}

\section{2 seasonally co-occurring herring Clupea harengus stocks}

3 Lotte A. W. Clausen ${ }^{1}$, Karl-Johan Stæhr ${ }^{2}$, Anna Rindorf ${ }^{1}$ and Henrik Mosegaard ${ }^{1}$

$4{ }^{1}$ National Institute of Aquatic Resources, DTU Aqua, Technical University of Denmark,

5 Charlottenlund Slot, DK-2920 Charlottenlund, Denmark

$6{ }^{2}$ National Institute of Aquatic Resource, DTU-Aqua, Technical University of Denmark, P.O. Box 101,

7 Nordsøen Forskerpark, DK -9850 Hirtshals, Denmark

8 RUNNING HEADLINE

9 GROWTH AND DISTRIBUTION OF HERRING 
ABSTRACT

11 The mechanisms most likely to determine the distribution of the two major herring Clupea harengus

12 stocks in their common early summer feeding ground in the Eastern North Sea, Skagerrak and Kattegat

13 were investigated through analysis of acoustic survey data from six consecutive years. No change was

14 detected in biomass of North Sea Autumn Spawning C. harengus (NSAS) over time whereas the

15 biomass of Western Baltic Spring Spawning C. harengus (WBSS) severely declined. Analyses of

16 centre of gravity by stock showed no change in NSAS distribution, whereas the WBSS changed to a

17 more western distribution over time. Contrary to previous perception of the juvenile migration, NSAS

18 were found to leave the study area already at the age between 1 and 2 and WBSS 1 year olds were

19 encountered in the Skagerrak. The estimated parameters of von Bertalanffy growth equations showed

20 marked differences between areas with fish in the eastern part of the area having the lowest size at age

21 at all ages. Further, their growth conditions appeared to deteriorate progressively over the period

22 studied. Both NSAS and WBSS showed the highest condition in the North Sea and Skagerrak while

23 condition was substantially lower in Kattegat. The westward movement of spring spawners over time

24 suggests that growth rate and possibly density of conspecifics influences the migration pattern and

25 distribution of $C$. harengus in the area. In contrast, there was no evidence to suggest that distribution

26 was constant over time within stocks or that distribution reflected size dependent limitations on

27 migration distance.

28 KEY WORDS: Acoustic surveys, Skagerrak, condition, migration, stock identity 
31 Atlantic herring Clupea harengus (L.) exhibit marked diversity over their distribution range, often 32 showing complex population structures with both genotypic and phenotypic variation (Bekkevold et al., 2005; Ruzzante et al., 2006) and a wide variety of migration patterns and growth forms (Secor et al., 2009; Brunel \& Dickey-Collas, 2010). Often two or more C. harengus stocks are targeted by a single fishery exploiting shoals of mixed population origin (Rosenberg \& Palmén, 1982; Clausen et al., 2007a; Payne et al., 2009) and population-specific exploitation rates may vary strongly both within and between years in response to combined effects of the spatial distribution of the fishery, spatio-temporal variation in the degree of population mixing and the relative biomass of the individual populations (Bekkevold et al., 2011). The degree of mixing between stocks is often variable and unpredictable which challenges successful spatio-temporal fishery management, particularly when populations are asynchronous in population dynamics (Payne et al., 2009). In these cases, it may be necessary to restrict fishing on one stock while the other stock can potentially sustain a larger fishing pressure. Managing fisheries of distinct $C$. harengus stocks is essential for several reasons: to maintain yields in the area, and to avoid stock depletion of the weaker component; and also to ensure the unique ecosystem function of $C$. harengus remains intact. One possibility is to use spatial management measures (Kell et al., 2009), but in order for this to be successful, knowledge of what determines the migratory behaviour and also the degree of mixing in different areas is essential.

C. harengus in the Skagerrak, the Kattegat and the Western Baltic (Figure 1) consist of a mixture of migrating populations with different life history characteristics. Of these, the populations within the North Sea Autumn Spawner stock (NSAS) and Western Baltic Spring Spawner stock (WBSS) are dominating summer foraging aggregations (Bekkevold et al., 2011). The two C. harengus stocks are 
52 targeted by a fishery in the Skagerrak and the Kattegat as well as the eastern parts of the North Sea 53 exploiting shoals of mixed population origin (Rosenberg \& Palmén, 1982; Payne et al., 2009; Clausen 54 et al., 2007b). The two populations follow specific migration patterns. Spawning of the WBSS occurs 55 in February-May with the most important spawning ground at the Greifswalder Bodden off the island 56 of Rügen (Biester 1979) where hydrographical retention keep larvae near local nursery areas in the 57 Western Baltic sea (Polte et al., 2013). The majority of the 2+ winter ring (wr) WBSS C. harengus are 58 assumed to migrate out of the subdivision 24 for the summer feeding grounds in Division IIIa and the eastern North Sea (Payne et al., 2009). During autumn, the WBSS return to the southern part of the Kattegat with the majority of the stock overwintering in the Sound (ICES subdivision 23) (Biester, 1979; Otterlind, 1987; Nielsen et al., 2001). NSAS C. harengus larvae, hatched in autumn along the UK east coast and in winter in the English Channel, drift from the spawning areas to subsequently metamorphose in spring near the nursery area ranging from the eastern North Sea into to the Skagerrak and the Kattegat (Burd, 1978; Heath et al., 1997). NSAS are assumed to remain in this area until $2 \mathrm{wr}$ when they start to mature and join the adult population feeding aggregation in the central and northern North Sea (Corten, 1986).

Atlantic C. harengus populations are often highly migratory with migration distance varying from a few $100 \mathrm{~km}$ to more than $1000 \mathrm{~km}$ (Slotte, 1999; Alerstam et al., 2003). These migrations are assumed to be adaptations to the local environmental conditions for increased success in spawning, growth or survival of offspring and/or maturing individuals. Migration take advantage of spatial and temporal differences in the distribution of resources (being food, spawning habitat availability, shelter for predators, etc.), and thus increase the fitness of the migrants (Harden Jones 1968; Chapman et al., 2012). For such behaviour to evolve, the benefits of using two or more different areas during a defined 
74 time-cycle must outweigh the costs of the migration. C. harengus may use predictive (genetic factors or 75 learning) and reactive (response to near field or state-space comparisons) orientation mechanisms 76 during migration (Harden Jones 1968, Fernö et al., 1998). A combination of reactive and predictive 77 orientation mechanisms may provide $C$. harengus with a flexible migration strategy, adapted to both 78 predictable and unpredictable conditions (Fernö et al., 1998). The underlying behavioural mechanism 79 could be influenced by “enviroregulation”, as suggested for scombrids (Reid et al., 1997), where the 80 fish select their immediate environments by swimming towards 'preferred' environmental conditions.

81 For C.harengus it has been shown that the intra-annual as well as inter-annual spatio-temporal pattern 82 of migrations may vary due to e.g. changes in environmental conditions (Fréon and Misund, 1999; 83 Dingle \& Drake, 2007), abundance (Fernö et al., 1998), fish age (Harden Jones, 1968; Fréon \& 84 Misund, 1999), condition (Slotte, 1999) or geographic variation in food availability (Kvamme et al., 85 2003).

The WBSS migration has been characterised as a summer feeding migration from spawning areas

87 distributed in fjords, sils and lagoons to the open waters of Kattegat and in particular the Skagerrak and Eastern parts of the North Sea (Figure 1), followed by a return to wintering areas (Nielsen et al., 2001; Payne et al., 2009). An age-related migration distance gradient has been reported for WBSS (Payne et al., 2009) with the older individuals migrating furthest into the outermost area of the Skagerrak and into the North Sea where the feeding conditions are supposed to be optimal (Maar et al., 2013).

92 However, given the several factors that have been shown to impact migration of C.harengus, the variability in migration distance (from the main spawning ground in the Western Baltic to the optimal

94 feeding grounds in the outer Skagerrak, Figure 1) between years for WBSS could depend on other factors than age. They e.g. may migrate further to get to the optimal feeding grounds when they are in 
96 better than average condition. Alternatively, migration distance may be determined by local carrying

97 capacity, in which case the proportion migrating towards attractive areas is higher when abundance is

98 low. It has been shown for NSAS that the preferred spawning more Southern spawning grounds are

99 used independent of the stock size, while the less preferred more Northern grounds are used when the

100 stock size is increasing (Corten 2001). Thus abundance related habitat selection may be occurring in

101 C.harengus as it has been shown for other species (e.g. Gadus morhua in the North Sea (Blanchard et 102 al., 2005).

103 The present study examines the observed distribution, growth and condition of $C$. harengus

104 encountered in the mixed feeding aggregations in the Eastern North Sea, the Skagerrak and the

105 Kattegat during summer. From the distribution of NSAS and WBSS during six consecutive years of

106 acoustic surveys, the migration mechanisms most likely to determine the early summer distribution of

107 the age classes of the two major stocks were investigated. The analysis tested four hypotheses to

108 understand mechanisms and implications of stock mixture in the summer feeding area:

109 H1: Migration is predetermined by predictive orientation mechanism (genetic factors or imprinting)

110 towards predefined areas typically characterised by bottom topography and persistent hydrographical

111 features acting as an attractor. Thus the distribution of a population will appear constant, albeit with

112 random variation.

113 H2: Migration is directed towards the area showing optimal growth conditions.

114 H3: Migration is size dependent with larger fish migrating further than small. Thus the proportion of

115 individuals of WBSS in the North Sea will have a larger body size on average than the individuals

116 encountered in the Kattegat, closer to the main spawning site. 
117 H4: Migration is a result of local carrying capacities. In this case, the abundance of NSAS and WBSS

118 in the preferred area will seem constant independent of total C.harengus abundance while vary in other 119 areas.

\section{METHODS}

\section{SURVEY DATA}

122 Hydro acoustic survey data on distribution, size and weight at age for C. harengus in the Kattegat and

123 the Skagerrak was available for the years 2006 to 2011 . The acoustic survey is part of the ICES

124 Coordinated Acoustic Survey in the Skagerrak and Kattegat, the North Sea, West of Scotland and the 125 Malin Shelf area (ICES, 2012).

126 Acoustic data were collected using a $38 \mathrm{kHz}$ echosounder with the transducer mounted in a towed body

127 towed at a target depth of 4-5 $\mathrm{m}$ depth. The raw acoustic data were pre-integrated into $1 \mathrm{~m}$ depth

128 samples for each ping and combined into 1 nautical mile datasets. The acoustic data were scrutinized in

129 depth layers for each nautical mile using special judging software which allows ignoring data from

130 layers and/or intervals with noise. In areas with acoustic input from plankton and jellyfish, manually

131 adjustable thresholds were applied to eliminate echoes from these objects. Final integration was

132 conducted from $3 \mathrm{~m}$ below the transducer to $1 \mathrm{~m}$ above the bottom or to a maximum depth of $150 \mathrm{~m}$.

133 The area with depth above $150 \mathrm{~m}$ contributes to $31 \%$ of the entire survey area. The integration yielded

134 the total backscattering cross section, $\mathrm{s}_{\mathrm{A}}$, of fish per square nautical mile for each nautical mile along 135 the survey track. 
136 For each ICES statistical rectangle, a mean areal back scattering, $\mathrm{s}_{\mathrm{A}}$-value, was calculated based on the

$137 \mathrm{~S}_{\mathrm{A}}$-values for all sampled nautical mile inside the area. This value is assumed to represent the whole

138 ICES statistical rectangle and is multiplied with its total area to obtain the total backscattering cross

139 section of fish in the ICES statistical rectangle. Based on allocated trawl hauls in each ICES statistical

140 rectangle or, if necessary, hauls from nearby ICES statistical rectangle, the species and length

141 composition of fish were identified. The mean back scattering cross section, TS, for fish in the subarea

142 was estimated based on the relative composition of fish in the mean catch and the length dependent TS-

143 relationships of C. harengus, S.spratus, Gadoid sp and S. scombrus (ICES, 2012). The total number of

144 fish in the subarea is then the total backscattering cross section of fish divided by the mean scattering

145 cross section of fish. The number of fish per species is assumed to be proportional to the contribution

146 of the given species in trawl hauls.

147 For each haul used for identification of species and length composition, the total catch was weighed,

148 sorted into species and total weight and length distribution per species was recorded. Clupeids were

149 measured to the nearest $0.5 \mathrm{~cm}$ total length below, and weighed to the nearest $0.1 \mathrm{~g}$ wet weight. In each

150 trawl haul 10 (if available) C. harengus per $0.5 \mathrm{~cm}$ length class were sampled and frozen for individual

151 laboratory determination of length, weight, age, and spawning type (NSAS or WBSS).

\section{BIOLOGICAL PARAMETERS}

153 In the laboratory, the length stratified subsamples of C. harengus were thawed and total length (nearest $154 \mathrm{~mm}$ ) and wet weight (0.01 gram) was recorded for each fish. The number of otolith winter rings (WR)

155 was determined using the procedure described in ICES (2003) and entered as a proxy for age. The

156 reason for using winter rings and not age in years is that the $C$. harengus are spawned either in autumn

157 (NSAS) or spring (WBSS) and given that the NSAS only have approximately 3 months to live before 
158 they experience their first winter, their first winter ring is not recordable and their first visible winter

159 ring is actually their second experienced winter (where they thus are 1.5 years old). The WBSS on the

160 other hand are less than 1 year old, when they lay down their first recordable winter ring. Otolith

161 microstructure (OM) was used to separate $C$. harengus stocks according to their different hatching time

162 using visual inspection of season-specific daily increment pattern in the larval otolith (Mosegaard \&

163 Madsen 1996; Clausen et al., 2007b). The method discriminates between sympatric C. harengus with

164 different spawning times (Brophy \& Danilowicz, 2002, 2003; Clausen et al., 2007b). Separation of

165 North Sea C. harengus from Western Baltic C. harengus in the Kattegat, the Skagerrak and the eastern

166 North Sea follows the assumption that all North Sea C. harengus are autumn/winter spawners and all

167 Western Baltic C. harengus are spring spawners as multiple populations with similar spawning time

168 cannot be distinguished with this analysis alone (Clausen et al., 2007). From 2010 onwards, harmonic

169 coefficients from Elliptic Fourier Analysis (EFA) of silhouette otolith images and non-parametric

170 nearest neighbour Discriminant Analysis (DA) were used together with OM to classify production

171 samples after calibration with an OM determined known-stock base-line (Burke et al., 2008). The OM

172 analysis is assumed to have less than 5\% misclassification error of the base-line (Clausen et al., 2007b)

173 and cross-validated self-assignment shows about $10 \%$ misclassification of the EFA based DA of the

174 production samples (ICES, 2013a).

\section{DISTRIBUTION}

176 Changes in distribution over time were evaluated using two different methods. Firstly, the yearly

177 biomass across winter ring groups by ICES statistical rectangle for each area and spawner type was

178 investigated to determine whether a trend over time could be detected. Secondly two indicators of

179 distribution were estimated; the centre of gravity of location by stock and age and changes in the area 
covered were investigated by estimating the average squared distance. The former indicator reflects whether the distributional area has changed geographical location whereas the latter indicator reflects

182 changes in the area covered by the stock. Centre of gravity was calculated by the mid-point latitude and

183 longitude in each ICES statistical rectangle weighted by the biomass of age categories in each ICES 184 statistical rectangle:

$185\left(C_{l o n, s, y, t}, C_{l a t, s, y, t}\right)=\left(\left(\sum_{i=0}^{N} B_{s, y, t, i} l o n_{i}\right)\left(\sum_{i=0}^{N} B_{s, y, t, i}\right)^{-1},\left(\sum_{i=0}^{N} B_{s, y, t, i} l a t_{i}\right)\left(\sum_{i=0}^{N} B_{s, y, t, i}\right)^{-1}\right)$

186 Where $C_{\text {lat,s,y,t }}$ and $C_{l o n, s, y, t}$ is the latitude and longitude of the center of gravity of spawner type $s$ with $t$

187 winter rings in year $y, B_{s, y, t, i}$ is the biomass of spawner type $s$ with $t$ winter rings in year $y$ in the $i$ th

188 rectangle and $\mathrm{lat}_{i}$ and $\mathrm{lon}_{i}$ is the mid latitude and longitude of ICES rectangle $i$, respectively.

189 Changes in the area covered were investigated by estimating the average squared distance, $D$, of a 190 biomass unit to the centre of gravity:

$$
D_{s, y, t}=\left(\sum_{i=0}^{N} B_{s, y, t, i}\left(\left(l a t_{i}-C_{l a t, s, y, t}\right)^{2}+\left(\operatorname{lon}_{i}-C_{l o n, s, y, t}\right)^{2}\right)\right)\left(\sum_{i=0}^{N} B_{s, y, t, i}\right)^{-1}
$$

192 This index is proportional to the area covered by $95 \%$ of the biomass if the distribution is a two-

193 dimensional normal distribution in space and even when the distribution is skewed or in other ways

194 deviate from normality, this indicator still reflects concentration of the stock (Rindorf \& Lewy, 2012).

195 The indicator is not responsive when the distribution is bimodal, but judging from the distribution, this 196 was not a problem in our analyses. 
197 Age related changes in the combined effects of mortality and migration were investigated by general

198 linear models of $\log$ (numbers) at age by area and type to compare slopes of the observed decline in

199 numbers with expected total mortality to infer immigration and emigration patterns among areas (F-

200 test, assuming normal distributed observations, McCullaugh \& Nelder 1989).. The difference in slope

201 between cohorts, years and areas were also investigated to determine whether different cohorts

202 experienced differences in mortality. Further, the presence of higher declines for older ages,

203 corresponding to higher mortality or emigration, was tested by estimating a second degree polynomial

204 relationship between age and $\log ($ numbers at age).

\section{GROWTH BY AREA}

206 The difference in length at age between area and spawner type was investigated to determine which of 207 the areas could be considered most favourable for growth or alternatively attract a specific growth type.

208 This was done through comparing length at age in a specific area with length at other ages and 209 estimating a von Bertalanffy growth equation across all years. This method will provide a combined 210 estimate of the effect of growth, size selective mortality and size specific net migration in an area. The 211 analysis is referred to here as an analysis of growth, which pertains to the assumption that size specific 212 net migration are of minor importance in comparison to growth in our results. This assumption is 213 discussed when interpreting the relationship between apparent growth and changes in distribution.

214 The relationship between area and spawner type and length at age was estimated through analyses of 215 the parameters of the von Bertalanffy growth equation using data from all years ignoring any cohort or 216 year effects. Von Bertalanffy growth equation for all areas and types was estimated as follows:

$217 \quad L_{a, s, t, i}=L_{\infty, a, s}\left(1-\exp \left(-K_{a, s}\left(t-t_{0, a, s}\right)\right)\right)+\varepsilon_{i}$ 
218 Where $t$ denotes number of winter rings, $L_{a, s, t, i}$ is the average total length in the ith observation (ICES

219 rectangle) at $t$ winter rings in area $a$ and spawner type $s, L_{\infty, a, s}$ is the average length of very old $C$.

220 harengus in area $a$ and spawner type $s, K_{a, s}$ is the growth rate in area $a$ and spawner type $s, t_{0, a, s}$ is the

221 theoretical age at which length is zero in area $a$ and spawner type $s$ and $\varepsilon_{i}$ is an error term,

$222 \varepsilon_{i} \in N\left(0, \sigma_{\varepsilon}\right)$. Parameters were estimated by least squares and recorded lengths at age 0 wr were

223 excluded from analyses. The effect of the factors area $a$ and spawner type $s$ on the parameters was

224 evaluated using an F-test and a significance level of 0.01 . This lower significance level was chosen to

225 accommodate the fact that the observations were not strictly independent (within-year correlation, see

226 results) and to avoid including factors which, though significant, explain a very low amount of the

227 variation. The length anomaly of the individual observation was defined as the residual length from the

228 estimated von Bertalanffy relationship and was calculated and used for further analyses of yearly

229 differences. Length-anomalies were investigated for trends by estimating the parameters in a

230 generalized linear model, investigating the effects of type and year for each area separately assuming a

231 normal distribution of anomalies.

232 CONDITION

233 An average condition index was calculated for each type, year, statistical rectangle and age by first

234 estimating the common weight-length relationship

$W=a L^{b}$ 
235 for all observations using a generalized linear model with gamma distributed error in mean weight to 236 estimate $b$. The average condition, $C_{i}$ of a given combination of type, year, statistical rectangle and age 237 (observation $i)$ was then estimated as

$C_{i}=W_{i} L_{i}^{-b}$

238 The difference in condition between spawner types, years and areas was investigated using ANOVA 239 whilst the trend over time in a generalized linear model with year as a linear variable, and the effect of 240 length on condition by area was tested between immature and mature C. harengus of both spawner 241 types using the same method.

\section{RESULTS}

244 DisTRIBUTION

245 C. harengus distribution at different scales was variable among years (Figure 2) as was the annual 246 proportion of spawner types by square. Analysis of distribution by year shows that the total distribution 247 and relative abundance shifts between years based on data collected during the summer acoustic cruise 248 (Figure 2), thus C.harengus do not necessarily congregate in the same area each summer. Total 249 biomass of spring spawners has been decreasing over the period in Kattegat (correlation between year 250 and biomass per rectangle $=-0.58, \mathrm{P}<0.0001$ ) and Skagerrak (correlation between year and biomass per 251 rectangle $=-0.30, \mathrm{P}<0.01$ ) (Figure 3). In contrast, there was no significant trend in the biomass of spring 252 spawners in the North Sea or in biomass of autumn spawners in any area $(\mathrm{P}>0.20$ in all cases, Figure 253 3). The decline in total biomass of spring spawners over the time period was $81.4 \%$ in Skagerrak and 
$25495.9 \%$ in Kattegat. As the biomass declined over time, the proportion of the total biomass for the area

255 which constituted spring spawners decreased accordingly. This decrease was significant in both the 256 North Sea $(\mathrm{P}<0.05)$ and Kattegat $(\mathrm{P}<0.01)$, but was below the significance level in Skagerrak $(\mathrm{P}>0.05)$.

258 The shift in distribution is also seen when examining the centre of gravity of the two spawner types 259 (Figure 4); there is no change in either latitude or longitude of the centre of gravity of autumn spawners 260 ( $\mathrm{P}>0.50$ in both cases). On the other hand, the longitude of the centre of gravity decreased significantly 261 for the spring spawners in the period corresponding to a westward shift in distribution (correlation=$2620.40, \mathrm{P}<0.05)$ whereas there was no significant change in latitude of center of gravity $(\mathrm{P}>0.23)$. The 263 centres of gravity by age class were significantly positively correlated along the latitudinal component $264(\mathrm{r}=0.61, \mathrm{P}<0.001)$, primarily driven by an age class related tendency of old $C$. harengus to be located in 265 more Northern (deeper waters) in Skagerrak and the North Sea (Figure 4). No such correlation existed 266 along the longitudinal dimension, but spring spawners had a significantly more easterly distribution 267 than autumn spawners for all ages $(\mathrm{P}<0.0001)$. The distribution coverage $(D)$ of the two stocks showed 268 year effects but no trend and coverage was not significantly correlated to biomass ( $\mathrm{P}>0.16$ in all cases).

269 Abundances expressed as log transformed numbers declined linearly with increasing age (Figure 5).

270 Slopes for autumn spawners exhibited no area effects $(\mathrm{P}>0.1)$, corresponding to a similar combined 271 effect of mortality and migration in all areas, whereas a significant area effect on slopes for spring 272 spawners was found $(\mathrm{P}<0.0001)$. Slopes were significantly non-linear for autumn spawners $(\mathrm{P}<0.0001)$, 273 whereas no significant non-linearity was found for spring spawners $(\mathrm{P}>0.1)$ that this pattern is also 274 found in the North Sea indicate that migration to all feeding areas generally takes place in all age 
275 groups including $1 \mathrm{wr}$. Slopes for autumn spawners were overall steeper (slope $=-1.37(\mathrm{se}=0.09))$ than

276 for spring spawners and substantially higher than the estimated F (fishing mortality) $+\mathrm{M}$ (natural

277 mortality) (0.66) in stock assessment would suggest (ICES, 2013b) indicating either a higher mortality

278 or an emigration of autumn spawners. All slopes were highly significant $(\mathrm{P}<0.01)$. Spring spawners in

279 the Skagerrak and the North Sea exhibited declines which were lower than those expected from stock

280 assessment estimates of total mortality $(0.39(\mathrm{se}=0.11)$ and $0.58(\mathrm{se}=0.07)$, in the North Sea and

281 Skagerrak, respectively), whereas spring spawners in the Kattegat had a significantly higher negative

282 slope $(1.14(\mathrm{se}=0.09))$ indicating either emigration from Kattegat to Skagerrak of the North Sea or

283 substantial differences in mortality between areas.

COMPARISON OF DISTRIBUTION, GROWTH AND SIZE AT AGE

285 Von Bertalanffy $K$ and $t_{0}$ did not differ significantly between spawner types or between areas $(\mathrm{P}>0.01$

286 in all cases), whereas $L_{\infty}$ differed both between spawner types and areas $(\mathrm{P}<0.0001$ in both cases $)$. This

287 indicates that length at age is similar for the youngest ages but becomes increasingly different between

288 types and areas with age (Figure 6). The variation in $L_{\infty}$ between areas explained $49 \%$ of the residual

289 variation in mean length around a common von Bertalanffy relationship, and variation in $L_{\infty}$ between

290 spawner types another $11 \%$, leading to a total of $60 \%$ of the residual variation explained by the final

291 model. The estimated $L_{\infty}$ in the North Sea did not differ significantly from that in the Skagerrak

292 ( $\mathrm{P}>0.1)$. However, to avoid introducing a growth period related bias in the subsequent analyses (see

293 methods), separate estimates were derived from the two areas. The resulting parameter estimates can be

294 seen in Table 1 . The variables $L_{\infty}, K$ and $t_{0}$ were highly correlated (all correlations $>0.75$ ) as is

295 generally the case when estimating von Bertalanffy parameters. 
296 The growth anomalies (the residuals from the reduced von Bertalanffy model) did not differ

297 significantly between spawner types in any of the areas ( $P>0.09$ in all areas, Figure 7$)$ and there was no 298 significant differences between years in the North Sea $(\mathrm{P}>0.1)$. However, the residuals varied 299 significantly between years in the Skagerrak and Kattegat ( $\mathrm{P}>0.005$ and $\mathrm{P}<0.0005$, respectively). The 300 year effect in residuals violates the assumption of independent residuals and hence the degrees of 301 freedom used when reducing the von Bertalanffy model are likely to be overestimated and parameter 302 error estimates are likely to be minimum estimates. In the Skagerrak, the differences did not result in a 303 trend over time $(\mathrm{P}>0.20)$, whereas the difference between years in Kattegat introduced a significant 304 negative trend in residuals $(\mathrm{P}<0.0001)$ with the average residual decreasing by $0.38 \mathrm{~cm}$ per year. 305 Hence, the Kattegat fish not only had the lowest $L_{\infty}$ and hence the lowest size at age at all ages, this 306 measure also declined progressively over the time period.

\section{CONDITION}

308 Condition differed significantly between spawner types $(\mathrm{P}<0.0001)$ with condition being $0.12^{*} 10^{-3}$ $309 \mathrm{~g}^{*} \mathrm{~cm}^{-3.26}\left(\mathrm{std}=0.02 * 10^{-3} \mathrm{~g}^{*} \mathrm{~cm}^{-3.26}\right)$ higher in autumn spawners than spring spawners. The difference 310 between areas was also highly significant $(\mathrm{P}<0.0001)$, with both types showing the highest condition in 311 the North Sea and the Skagerrak while condition was substantially lower in the Kattegat (Table 2). A 312 significant correlation was found between condition of the two spawner types by ICES rectangle year 313 and age within all age groups with 1 wr having the highest correlation $\mathrm{r}=0.81 \mathrm{p}<0.0001$, and in all cases $314 \mathrm{r}>0.4, \mathrm{P}<0.05$ (Figure 8).

315 Condition decreased significantly with age $\left(-0.070 * 10^{-3} \mathrm{~g}^{*} \mathrm{~cm}^{-3.26}\right.$ per year, standard error $=0.007 * 10^{-3}$ $\left.316 \mathrm{~g}^{*} \mathrm{~cm}^{-3.26}\right)$ with no significant difference in the decrease between areas $(\mathrm{P}>0.1)$ or spawner types 
317 ( $\mathrm{P}>0.5)$. No significant correlation between condition by age class and biomass per ICES rectangle was

318 found for any of the two spawner types, indicating local density independence of condition.

319 For both spring and autumn spawners condition decreased significantly with age. In addition to a 320 significant area effect $(\mathrm{P}<0.0001)$, spring spawners exhibited a significantly different relationship with 321 residual length for juvenile and adult spring spawners over all areas, showing a non-significant 322 negative slope for $1-2 \mathrm{wr}$ and a significant positive slope for $3-5 \mathrm{wr}$ (slopes $-0.06, \mathrm{R}^{2}=0.06$ and 0.21 , $323 \mathrm{R}^{2}=0.33$ respectively, $\mathrm{P}<0.005$ for slopes being equal). No trends in condition with growth rate and no 324 significant differences between juveniles and adults were found in autumn spawners $(\mathrm{P}>0.1)$.

\section{DISCUSSION}

This study showed significant variation in the distribution of western Baltic spring spawners and North Sea autumn spawners in their summer feeding area, rejecting the hypothesis that the summer feeding migration of these two stocks in the study area is predetermined by predictive orientation mechanism (H1). C. harengus in the Skagerrak and the Eastern North Sea were in general significantly larger than in the Kattegat and the former areas exhibited consistently higher abundance than Kattegat. Spring spawners migrated to the Skagerrak and the North Sea from 1wr whereas autumn spawners appeared in all three areas from the earliest age but started to leave all areas at least between 1 and $2 \mathrm{wr}$. Size at age did not differ between areas at $0 \mathrm{wr}$, but differences emerged with increasing age, supporting the conclusion of differences in growth rate while indicating that migration was at least not initially size dependent. Thus the migration appeared to be size dependent directed towards the area showing optimal growth conditions, confirming hypotheses H2 and H3 of this study. Density in the low growth 
corresponding with a density dependent migration towards areas where growth rate appears to occur at

a faster rate or an increased emigration as growth conditions deteriorated. This indicates that the

summer feeding migration is a result of local carrying capacities given that the abundance of NSAS and

341 WBSS in the preferred area was independent of total C.harengus abundance while it significantly

342 decreased with total abundance in Kattegat; thus confirming hypothesis $\mathrm{H} 4$ of the study.

343 Estimated biomass for spring spawners declined substantially in both the Kattegat and the Skagerrak

344 over the period, whereas no trends were found for autumn spawner biomasses in any of the three areas.

345 The cause of the decline was likely a combination of high fishing pressure and decreasing recruitment

346 during the first decade of the 2000s (ICES, 2013b). The spring spawners apparently kept migrating as

347 far as the North Sea at the same time as they became fewer and smaller at age in the Kattegat, thus the

348 remaining part of the stock seemed to prefer feeding areas further from the spawning grounds

349 regardless of initial size. Areal coverage of the spring spawning stock did not co-vary with decreasing

350 biomasses and thus did not follow the hypothesis of contracting feeding range with declining

351 population size (Murphy, 1977).

352 The North Sea and Skagerrak parts of the summer-feeding area were at a constant advantage in terms 353 of the largest size at age and the highest condition across years, independent of spawning type. The

354 difference in $L_{\infty}$ between the North Sea-Skagerrak and the Kattegat was around $3 \mathrm{~cm}$ for both spawning 355 types and even in years with positive size at age anomaly in the Kattegat, they still exhibited the 356 smallest size as the anomaly never exceeded $1 \mathrm{~cm}$ (Table 1, figure 7). Thus, the Eastern North Sea357 Skagerrak likely provided the best growth opportunities for C. harengus irrespective of spawning type 358 and year. C. harengus is known to be a size selective planktivore, preferring large-sized e.g. calanoid 359 zooplankton species, as seen in the Baltic (Flinkman et al., 1998), the North Sea (Maravelias et al., 
2000; Last, 1989; Segers et al., 2007) the Norwegian Sea and the North Atlantic (Dalpadado et al.,

361 2000; Gislason \& Astthorsson, 2002) and the Gulf of St. Lawrence (Darbyson et al., 2003). The

362 available literature and data on the zooplankton community in the Kattegat-Skagerrak area suggest that

363 higher concentrations of egg producing adult stages of the Calanus finmarchicus (Gunnerus) follow

364 frontal zones coupled to the Skagerrak loop of Jutland current and low saline waters entering the

365 Skagerrak from the Kattegat (Maar et al., 2013). Also, the community of larger zooplankton changes in

366 the transition zone between the Baltic and the North Sea; euphausiids increase significantly in size

367 from Kattegat to Skagerrak (Buchholz \& Boysen-Ennen, 1988). Thus supremacy in food quality and

368 availability in the Eastern North Sea-Skagerrak may explain at least some of the difference observed

369 here in growth pattern between areas.

370 C. harengus biomass dominates the pelagic fish community in the Skagerrak and surrounding areas,

371 but $C$. harengus condition and apparent growth rate exhibited divergent co-variation with C. harengus

372 abundance in the three sub-areas. There was an increase in condition in the North Sea and Skagerrak

373 concurrent with the decrease in biomass in the Skagerrak, whereas both condition and size at age of

374 spring spawners in Kattegat decreased over the time-period concurrently with a marked decrease in

375 biomass. Evidence of density dependent growth has been found for several stocks e.g. Icelandic

376 summer spawners (Oskarsson, 2008), Norwegian spring-spawners (especially for immature fish;

377 Toresen, 1990), Georges Bank (Melvin \& Stephenson, 2007), and Baltic Sea Atlantic C. harengus

378 (Casini et al., 2006), but not for others (Gulf of Finland, and southern Gulf of St Lawrence, as reviewed

379 in Melvin \& Stephenson (2007). C. harengus in the Eastern North Sea and Skagerrak did not display

380 any trend in growth rate over time. In contrast, the condition of C. harengus in the Kattegat was

381 consistently poorer than that of C. harengus in the Skagerrak and the Eastern North Sea across years 
382

and spawning type, which supports the conclusion that Kattegat is less optimal for summer growth. The opposing trends in condition in Kattegat and Skagerrak concurrent with the order of magnitude decrease in the Kattegat and Skagerrak biomasses also indicates that the decrease in size at age in the south-eastern part of the summer distribution area is unrelated to density dependence in the two stock sub units.

A decrease in length at age also acts to decrease biomass. However, the decrease in asymptotic length in Skagerrak and Kattegat was $1.7 \mathrm{~cm}$ and $2.2 \mathrm{~cm}$, respectively, corresponding to about $18 \%$ and $25 \%$ decrease in individual weight, which is clearly insufficient to explain the $81 \%$ and $96 \%$ decrease in biomass in the Skagerrak and the Kattegat, over the entire time period. The latest stock assessment estimates of the total Western Baltic Spring Spawner total biomass shows a decline of 47\% from 2006 to 2011, whereas North Sea Autumn Spawner total biomass has increased by about 17\% (ICES, 2013b). A marked difference in size selectivity and intensity of both fishery and natural predators in Kattegat compared to Eastern North Sea and Skagerrak could also explain the change in biomass and different growth rate pattern. However, since 2002, the C. harengus fishery in the area has been concentrated in the more north-western part of Skagerrak (ICES, 2013b). Although the predation field may differ between the areas, it seems unlikely that predators should be responsible for an increasing outtake of larger C. harengus in the Kattegat only and hence be the cause of the decreasing length at age.

A significant year effect on residual length in both the Kattegat and the Skagerrak is only matched by a similar cohort effect in the Skagerrak, indicating that the stock components in the Kattegat are not persistent among years and they most likely redistribute to the Skagerrak at older ages This is further supported by the much steeper slope of the log transformed cohort numbers for both spawning types in 
404 the Kattegat. The variation in annual center of gravity for both stocks in the area is much greater than 405 for the autumn spawners' center of gravity in the North Sea during the same period and time of the year 406 (ICES, 2013b). The lack of correlation between biomass and distributional trends in the transition area 407 indicates that the search for the best feeding opportunities shifts the population distribution annually. 408 This is overlaid by a westward migration tendency of the autumn spawners and a gradual shift towards 409 deeper waters with increasing size for both spawning types. Hence, changes in biomass levels and 410 centres of gravity as well as patterns in size at age all point to a redistribution of C. harengus towards 411 more north-western parts of the summer feeding area during a period when the spring spawner 412 population declined. The observed population mobility among years indicates that local changes in 413 environmental conditions may be the drivers behind the general distribution pattern.

414 Sudden density dependent changes in growth rate are not uncommon in C. harengus and may appear as 415 a regime shift mediated through interspecific clupeid competition as in the Baltic (Möllmann et al., 416 2005) or intraspecific competition in the Gulf of Riga (Raid et al., 2010) where an increase in C. 417 harengus abundance in the late 1980s changed growth conditions to much smaller maximum size at 418 age. Further, a large $C$. harengus year-class may suppress the individual growth in the cohort and exist 419 as a marker for the entire life span as seen for the 1904 year-class of Norwegian spring spawners (Hjort 420 1914) and the 2000 year-class of the North Sea autumn spawners (ICES, 2013b).

421 The two C. harengus stocks in the area exhibit marked differences in their innate migration behaviour 422 that probably reflect stock-specific differences in spawning time and location. Autumn and winter 423 spawned C. harengus larvae drift during winter from the western and southern parts of the North Sea 424 towards their later nursery areas including the transition area of the eastern North Sea, the Skagerrak 425 and the Kattegat (Johannesen \& Moksness 1988). Larvae from the spring spawning stock are dispersed 
426 locally (Polte et al., 2013) and juveniles therefore actively have to migrate to the nursery grounds in the 427 transition area.

428 The proportion of spring spawners increases at $2 \mathrm{wr}$ compared to $1 \mathrm{wr}$ in the Eastern North Sea part of 429 the summer feeding area (ICES, 2013b), and it has therefore generally been assumed that the full 430 migration distance of the spring spawning stock is first attained at 2 wr (Payne et al., 2009). However, 431 our analysis of slope of log abundance at age with no significant nonlinearity in spring spawners 432 indicates that 1 wr spring spawners migrate as far towards the North Sea as their older relatives. The 433 higher slope in the corresponding analysis of autumn spawners indicate that juveniles of this stock 434 leave the nursery area in high numbers already between $1 \mathrm{wr}$ and $2 \mathrm{wr}$, leading to an increase in spring 435 spawner proportion from 1 wr to 2 wr in the Eastern North Sea area.

436 During the growing season, juvenile C. harengus join schools of similar sized individuals (Nøttestad et 437 al., 1999). The findings here indicate that initially juveniles from both stocks form mixed schools in the 438 area and gradually relocate according to experienced growth potential. A higher occurrence of mixed 439 juvenile schools in the summer feeding area early in life when the two C. harengus types are of the 440 same size would explain the higher correlation in condition between spring and autumn spawners at 1 441 wr. Further the lack of positive correlation between condition and residual size in juvenile spring 442 spawners as opposed to adult spring spawners could be explained if spring spawner juveniles with the 443 highest growth potential would school with the largest and fastest swimming autumn spawner 444 juveniles.

445 The apparent advantage in terms of growth rate associated with the western parts of the summer 446 distribution area would mean that to optimize growth, individual $C$. harengus should spend the summer 
447 feeding period there. As the difference in size at age in the two areas in terms of both length and 448 condition increased over time, the distribution concurrently shifted towards the high growth areas 449 (Figure 7). Given that the autumn spawners did not systematically shift distribution over time, the 450 distribution of the $C$. harengus biomass did not simply follow a given distribution of food items. Thus 451 for the spring spawners, the determining factor for the amplitude and direction of the summer feeding 452 migration is likely to differ from the determinant of the autumn spawner distribution.

453 The summer feeding migration pattern observed in the spring spawners appears to be consistent with 454 maximization of growth rate in the individual C. harengus where C. harengus with increasing age and 455 size progressively abandon the sub optimal feeding areas in the Kattegat to concentrate further to the 456 north-west. State dependent migration is a well-known behaviour in fish (Harden Jones, 1968) and for 457 C. harengus it has been well documented for Norwegian Spring Spawning C. harengus both 458 concerning spawning migration (Slotte \& Fiksen, 2000) and summer feeding migrations (Kvamme et 459 al., 2003). In our study, the extent of the migration is probably defined at an early stage since the 460 differences in growth rates in the areas emerge with age (Figure 6). Thus the advantage in terms of 461 growth rate continues through life for the individuals reaching furthest in the migration. However, 462 given the westerly change in distribution over time (Figure 4) during the years where the growth 463 conditions in Kattegat continues to worsen, indicates that this pattern can change and C. harengus can 464 benefit from improved opportunities for growth by changing their migration pattern, just as seen in 465 Norwegian Spring Spawners (Kvamme et al., 2003). The observed westward changes in distribution of 466 the spring spawning $C$. harengus may be caused either by increased mortality of fish in Kattegat, by a 467 general decrease in the stock combined with an increase in the migration distance of the average fish or 468 by a combination of the two. An increase in migration could be induced by generally increased size at 
age or by the diminishing density dependent competition for resources in Skagerrak/North Sea as

470 density decreases. The former seems unlikely as length at age residuals decreased in both Skagerrak

471 and Kattegat, indicating that the fish did not need to have a threshold condition/size to move to

472 Skagerrak. In that case, size at age would have remained unchanged in Skagerrak. There could be

473 indications of a threshold size to move to the North Sea as no change in residual length was seen here.

474 If density dependent competition for resources has limited migration of smaller fish so far, this effect

475 should diminish in Skagerrak in later years, given the reduction in biomass recorded, leaving room for

476 more fish to move to this area. If these fish were among the larger fish in Kattegat, this movement

477 would act to decrease length at age in both Skagerrak (now receiving smaller fish) and Kattegat (now

478 losing larger fish). If the effect is furthermore the result of accumulating effects on length at age at

479 different ages, this could explain why biomass in an individual year in spite of underlying density

480 dependent effect was not significantly related to residual length. Thus, a degree of size dependence of

481 migration distance may still exist though this does not show up in the current investigation.

482 The advantage in terms of growth rate in western areas and the westward displacement of the

483 distribution of spring spawners over time suggests that both growth rate and density of conspecifics

484 may influence the migration pattern of WBSS C. harengus. In a trade-off between migration

485 expenditure and energy accumulation for growth and later reproduction local $C$. harengus with a low

486 growth potential (expressed as a lower condition in all years) will not experience a net energy gain by

487 increasing migration distance and moving further out than Kattegat, displaying the same differences in 488 trade-off between migration length and spawning success as observed in migrating and non migrating 489 C. harengus in a Norwegian fjord (Johannesen et al., 2009). 
490 This study demonstrates a growth related migration of both spring and autumn spawners directed 491 towards the more western parts of the summer feeding area, where the growth conditions are optimal. 492 This is a change in the perception of the mixture of $C$. harengus during summer in the area and it will 493 have consequences for the management of the fishery on these stocks during summer. The fishery in 494 the area takes mixed catches of juveniles from the two stocks whereas adult C. harengus in the catches 495 predominantly consist of spring spawners. The results of this study imply that catches of C. harengus in 496 these areas with optimal growth conditions will consist of a faster-growing part of the stocks, which 497 should be considered by the management of the C. harengus fishery. A mixed fishery targeting specific 498 parts of a stock may lead to a reduction in the capacity of the stock to withstand climate variability and 499 change; i.e. the resilience of the stock (Schindler et al., 2010). The distribution of the C. harengus in 500 the area is thus more influenced by growth of the individual fish than the age of the fish. The change 501 from the earlier perception of a limited 1 wr migration (see Payne et al., 2009) to a full dispersion of all 502 juvenile spring spawners to the entire summer feeding area, combined with the finding of progressive 503 juvenile autumn spawner emigration will lead to different mixing of the stocks in juvenile fishery than 504 previously assumed. This will influence the current procedure of predicting catch options to be 505 considered in the management of the C. harengus by-catch in the small meshed sprat fishery in 506 Division IIIa (ICES 2013a) given the need for considering the varying mixture of juvenile C. harengus. 507 This study, thus, supports the notion (e.g. Schindler et al., 2010; Bekkevold et al., 2011) that marine 508 fish management needs to incorporate knowledge about individual population dynamics to allow 509 sustainable exploitation of all substocks. 
512 The research was partly financed and conducted as part of the Fehmarn Belt Science Provision Project 513 and the E.U. 7th Framework through the Capacities programme GAP2 Connecting Science, 514 Stakeholders and Policy. We thank the crew on R/V Dana participating in the yearly acoustic surveys 515 and the laboratory personnel at DTU Aqua for processing the over 12,000 herring individuals and 516 Casper W. Berg for providing the map of herring distributions. 


\section{REFERENCES}

519 Alerstam, T., Hedenström, A. \& Akesson, S. (2003). Long-distance migration: evolution and determinants. Oikos 103, 247-260.

Aro, E. (1989). A review of fish migration patterns in the Baltic. Rapports et Procès-Verbaux des Réunions du Conseil 190, 72-96.

Bekkevold, D., Andre, C., Dahlgren, T. G., Clausen, L. A. W., Torstensen, E., Mosegaard, H., Carvalho, G. R., Christensen, T. B., Norlinder, E., \& Ruzzante, D. E. (2005). Environmental Correlates of Population Differentiation in Atlantic Herring. Evolution, 59, 2656-2668

Bekkevold, D., Clausen, L. A. W., Mariani, S., André, C., Hatfield, E. M. C., Torstensen, E., Ryman, 528 N., Carvalho, G. R., \& Ruzzante, D. E. (2011). Genetic mixed-stock analysis of Atlantic herring populations in a mixed feeding area. Marine Ecology Progress Series 442, 187199.

Biester, E. (1979). Der Frühjahrshering Rügens—-seine Rolle in der Fischerei der Ostsee und in den Übergangsgebieten zur Nordsee. Doctoral thesis, Wilhelm-Pieck University of Rostock.

Bierman, S. M., Dickey-Collas, M., van Damme, C. J. G., van Overzee, H. M. J., Pennock-Vos, M. G., Tribuhl, S. V., \& Clausen, L. A. W. (2010). Between-year variability in the mixing of North Sea herring spawning components leads to pronounced variation in the composition of the catch. ICES Journal of Marine Science 67, 885-896. 
537 Blanchard, J.L., Mills, C., Jennings, S., Fox, C.J., Rackham, B.D., Eastwood, P.D., O’Brien, C.M.

538 (2005). Distribution-abundance relationships for North Sea Atlantic cod (Gadus morhua): observation versus theory. Canadian Journal of Fisheries and Aquatic Science 62, 20012009

Block, B. A., Teo, S. L. H., Walli, A., Boustany, A., Stokesbury, M. J. W., Farwell, C. J., Weng, K. C., Dewar, H., \& Williams, T. D. (2005). Electronic tagging and population structure of Atlantic bluefin tuna. Nature 434, 1121-1127.

Brielmann, N. (1989). Quantitative analysis of Ruegen spring-spawning herring larvae for estimating 0-group herring in Subdivisions 22 and 24. Rapports et Procès-Verbaux des Réunions du Conseil 190, 271-275.

Brophy, D., \& Danilowicz, B. S., (2002). Tracing populations of Atlantic herring (Clupea harengus L.) in the Irish and Celtic Seas using otolith microstructure. ICES Journal of Marine Science 59, 1305-1313.

Brophy, D., \& Danilowicz, B. S., (2003). The influence of prerecruitment growth on subsequent growth and age at first spawning in Atlantic herring (Clupea harengus L.). ICES Journal of Marine Science 60, 1103-1113.

Brunel, T., \& Dickey-Collas, M., (2010). Effects of temperature and population density on von Bertalanffy growth parameters in Atlantic herring: a macro-ecological analysis. Marine Ecology Progress Series 405, 15-28. 
556 Buchholz, F. \& Boysen-Ennen, E. (1988). Meganyctiphanes norvegica (Crustacea: Euphausiacea) In the Kattegat: Studies on the horizontal distribution in relation to hydrography and zooplankton. Ophelia 29, 71-82

Burd, A. C. (1978). Long term changes in North Sea herring stocks. Rapports et Procès-Verbaux des Réunions du Conseil 172, 137-153.

Burke, N., Brophy, D., \& King, P.A. (2008). Shape analysis of otolith annuli in Atlantic herring (Clupea harengus); a new method for tracking fish populations. Fisheries Research 91, 133-143.

Casini, M., Cardinale, M., \& Hjelm, J. (2006). Inter-annual variation in herring, Clupea harengus, and sprat, Sprattus sprattus, condition in the central Baltic Sea: what gives the tune? Oikos $112,638-650$

Chapman, B.B., Hulthén, K., Brodersen, J., Nilsson, P.A., Skov, C., Hansson, L.A., \& Brönmark, C. (2012). Partial migration in fishes: causes and consequences. Journal of Fish Biology, 8, $456-478$

Clausen, L. A. W, Bekkevold, D., Hatfield, E. M. C. and Mosegaard, H. (2007b). Application and 574 validation of otolith microstructure as a stock identification method in mixed Atlantic 
herring (Clupea harengus L) stocks in the North Sea and western Baltic. ICES Journal of Marine Science 64, 377-385.

Corten, A. (1986). On the causes of the recruitment failure of herring in the central and northern North Sea in the years 1972-1978. Journal du Conseil International pour l'Exploration de la Mer, 42, 281-294.

Corten, A. (2001). The role of "conservatism" in herring migrations. Reviews in Fish Biology and Fisheries 11, 339-361.

Dalpadado, P., Ellertsen, B., Melle, W., \& Dommasnes, A. (2000). Food and feeding conditions of Norwegian spring-spawning herring (Clupea harengus) through its feeding migrations. ICES Journal of Marine Science 57, 843-857.

Darbyson, E., Swain, D. P., Chabot, D., \& Castonguay, M. (2003). Diel variation in feeding rate and prey composition of herring and mackerel in the southern Gulf of St Lawrence. Journal of Fish Biology 63, 1235-1257.

Dingle, H. \& Drake, A. (2007). What Is Migration? BioScience, 57, 113-121.

Fernö, A., Pitcher, T.J., Melle, W., Nøttestad, L., Mackinson, S., Hollingworth, C., \& Misund, O.A. (1998). The challenge of the herring in the Norwegian Sea: making optimal collective spatial decisions. Sarsia 83:149-167

Flinkman, J., Aro, E., Vuorinen, I., \& Viitasalo, M. (1998). Changes in northern Baltic zooplankton and herring nutrition from 1980s to 1990s: top-down and bottom-up processes at work. Marine Ecology Progress Series 165, 127-136. 
595 Forseth, T., Næsje, T. F., Jonsson, B., \& Hårsaker, K. (1999). Juvenile migration in brown trout: a 596 consequence of energetic state. Journal of Animal Ecology 68, 783-793.

597 Fréon, P. \& Misund, O. A. (1999). Dynamics of Pelagic Fish Distribution and Behaviour: Effects on 598 Fisheries and Stock Assessment. Fishing News Book. Blackwell Science Ltd. London.

599 Gislason, A. \& Asthorsson, A.S. (2002). The food of Norwegian spring-spawning herring in the 600 western Norwegian Sea in relation to the annual cycle of zooplankton. Sarsia 87, 236601247.

602 Harden Jones, F. R. (1968). Fish Migration. Edward Arnold Publishers Ltd. London 603 Heath, M., Scott, B., \& Bryant, A. D. (1997). Modelling the growth of herring from four different 604 stocks in the North Sea. Journal of Sea Research 38, 413-436.

605 Hjort, J. (1914). Fluctuations in the great fisheries of northern Europe. Rapports et Procès-Verbaux des $606 \quad$ Réunions du Conseil 20, 1-228.

607 ICES (1962). Recommendation adopted by the Herring Committee (Appendix). Rapports et Procès$608 \quad$ Verbaux des Réunions du Conseil 1, 71-73.

609 ICES (2003). Report of Herring Assessment Working Group for the Area South of $62^{\circ}$ N. ICES CM 610 2003/ACFM: 17. Available from www.ices.dk

611 ICES (2011). Report of the Workshop on the evaluation of the long-term management plan for North 612 Sea herring. ICES CM 2011/ACOM:55. Available from www.ices.dk 
613 ICES (2012). Report of the Working Group for International Pelagic Surveys. ICES CM 2012/SSGESST: 21. Available from www.ices.dk

615 ICES (2013a) Report of the Benchmark Workshop on Pelagic Stocks. ICES CM 2013/ACOM:46. $616 \quad$ Available from $\underline{w w w . i c e s . d k}$

617 ICES (2013b). Report of the Herring Assessment Working Group for the Area South of 62 N. ICES 618 CM 2013/ACOM:06 Available from www.ices.dk

619 Jennings, S., \& Beverton, R. J. H. (1991). Intraspecific information in the life history tactics of Atlantic 620 herring (Clupea harengus L.) stocks. ICES Journal of Marine Science 48, 117-125.

621 Johannessen, A., \& Moksness, E. (1991). Herring larvae (Clupea harengus) in the Skagerrak area from 622 December 1987 to April 1988. Fisheries Research 11, 155-170.

623 Johannessen, A., Nøttestad, L., Fernö, A., Langård, L., \& Skaret, G. (2009). Two components of 624 Northeast Atlantic herring within the same school during spawning: support for the 625 existence of a metapopulation? ICES Journal of Marine Science 66, 1740-1748.

626 Jonsson B. \& Jonsson N. (1993). Partial migration: niche shift versus sexual maturation in fishes. $627 \quad$ Reviews in Fish Biology and Fisheries 3, 348 -365.

628 Jørgensen, H. B. H., Hansen, M. M., \& Loeschcke, V. (2005). Spring-spawning herring (Clupea 629 harengus L.) in the southwestern Baltic Sea: do they form genetically distinct spawning 630 waves? ICES Journal of Marine Science 62, 1065-1075. 
631 Kell. L. T., Dickey-Collas, M., Hintzen, N. T., Nash, R. D. M., Pilling, G. M., \& Roel, B. A. (2009). Lumpers or splitters? Evaluating recovery and management plans for metapopulations of 633 herring. ICES Journal of Marine Science 66, 1776-1783.

634 Kvamme, C., Nøttestad, L., Fernö, A., Misund, O. A., Dommasnes, A., Axelsen, B. E., Dalpadado, P., 635 \& Melle, W. (2003). Migration patterns in Norwegian spring-spawning herring: why 636 637 young fish swim away from the wintering area in late summer. Marine Ecology Progress Series 247, 197-210.

Last, J. M. (1989). The food of herring, Clupea harengus, in the North Sea, 1983-1986. Journal of Fish Biology 34, 489-501.

Lett, P. F., \& Kohler, A. C. (1976). Recruitment: a problem of multispecies interaction and environmental perturbations with special reference to Gulf of St. Lawrence Atlantic herring (Clupea harengus harengus). Journal of the Fisheries Research Board of Canada

644 Maar M., Møller, E.F., Gürkan, Z., Jónasdottir, S.H., \& Nielsen, T.G. (2013). Sensitivity of Calanus 645 spp. copepods to environmental changes in the North Sea using life-stage structured 646 models. Progress in Oceanography 111, 24-37 33, 1353-1371. 
649 Maravelias, C. D., Reid, D. G. and Swartzman G. (2000). Seabed substrate water depth and 650 zooplankton as determinants of the prespawning spatial aggregation of North Atlantic 651 herring. Marine Ecology Progress Series 195, 249-259.

652 McCullaugh, P., and Nelder, J.A. 1989. Generalized linear models. Monographs in Statistical $653 \quad$ Applications and Probability 37

654 Melvin, G. D., \& Stephenson, R. L. (2007). The dynamics of a recovering fish stock: Georges Bank 655 herring. ICES Journal of Marine Science 64, 69-82.

656 Misund, O. A., Vilhjálmsson, H., iJákupsstovu, S. H., Røttingen, I., Belikov, S., Ástthorsson, Ó., 657 Blindheim, J., Jónsson, J., Krysov, A., Malmberg, S. A., \& Sveinbjørnsson, S. (1998). 658 Distribution, migration and abundance of Norwegian spring spawning herring in relation 659 660 to the temperature and zooplankton biomass in the Norwegian Sea as recorded by coordinated surveys in spring and summer 1996. Sarsia 83, 117-127.

Mosegaard, H. \& Madsen, K. P. (1996). Discrimination of mixed herring stocks in the North Sea using vertebral counts and otolith microstructure. ICES CM 1996/H:17. Available from www.ices.dk

Möllmann, C., Kornilovs, G., Fetter, M., \& Köster F. W. (2005). Climate, zooplankton, and pelagic 665 fish growth in the central Baltic Sea. ICES Journal of Marine Science 62, 1270-1280.

666 Murphy, G. (1977). Clupeoids. In: Fish population dynamics. (Gulland, J. A., ed) pp. 283-308. John 667 Wiley, London. 
668 Nielsen, J. R., Lundgren, B., Jensen, T. F., \& Stæhr, K. J. (2001). Distribution, density and abundance 669 of the western Baltic herring (Clupea harengus) in the Sound (ICES Subdivision 23) in 670 relation to hydrographical features. Fisheries Research 50, 235-258.

671 Nøttested, L., Aksland, M., Beltestad, A., Fernø, A., Johannessen, A., \& Misund, O.A. (1996).

672 Schooling dynamics of Norwegian spring spawning herring (Clupea Harengus L.) in a 673 coastal spawning area. Sarsia $\mathbf{8 0}, 277-284$.

674 Nøttestad, L., Giske, J, Holst, J. C. \& Huse, G. (1999). A length-based hypothesis for feeding 675 migrations in pelagic fish. Canadian Journal of Fisheries and Aquatic Science 56, 26-34.

676 Nøttestad, L., Misund, O. A., Melle, W., Hoddevik Ulvestad, B. K., \& Orvik, K. A. (2007). Herring at 677 the Arctic front: influence of temperature and prey on their spatio-temporal distribution 678 and migration. Marine Ecology 28, 123-133. spawning herring Clupea harengus L. Journal of Fish Biology 72, 2655-2676.

681 Otterlind, G. (1987). On the Öresund herring and related population problems. Meddelande från 682 Havsfiskelaboratoriet, Fiskeristyrelsen 322.

Payne, M. R., Clausen, L. W., \& Mosegaard, H. (2009). Finding the signal in the noise: objective dataselection criteria improve the assessment of western Baltic spring-spawning herring. 685 ICES Journal of Marine Science 66, 1673-1680. 
686 Petitgas, P., Secor, D. H., McQuinn, I., Huse, G., \& Lo, N. (2010). Stock collapses and their recovery: 687 688 mechanisms that establish and maintain lifecycle closure in space and time. ICES Journal 689 Polte, P., Kotterba, P., Hammer C., \& Gröhsler, T. (2013). Survival bottlenecks in the early ontogenesis 690 691 of Marine Science 67, 1841-1848.

692 Raid, T., Kornilovs, G., Lankov, A., Nisumaa, A., Shpilev, H., \& Järvik, A. (2010). Recruitment 693 694 dynamics of the Gulf of Riga herring stock: density-dependent and environmental effects. 695 Reid, D., Turrell, W. R., Walsh, M., \& Corten, A. (1997). Cross-shelf processes north of Scotland in 696 ICES Journal of Marine Science 67, 1914-1920. relation to the southerly migration of Western mackerel. ICES Journal of Marine Science $\mathbf{5 4}, 168-178$.

Rindorf, A. \& Lewy, P. (2012). Estimating the relationship between abundance and distribution. Canadian Journal of Fisheries and Aquatic Sciences 69, 382-397, doi: 10.1139/F2011153

701 702 703

Rosenberg, R., \& Palmén, L.E. (1982) Composition of herring stocks in the Skagerrak-Kattegat and the relations of these stocks with those of the North Sea and adjacent waters. Fisheries Research 1, 83-104. 
704 Ruzzante, D. E., Mariani, S., Bekkevold, D., André, C., Mosegaard, H., Clausen, L. A., ... \& Carvalho, 705 G. R. (2006). Biocomplexity in a highly migratory pelagic marine fish, Atlantic herring. 706 Proceedings of the Royal Society B: Biological Sciences 273, 1459-1464.

707 Secor, D. H., Kerr, L. A., \& Cadrin, S. X. (2009). Connectivity effects on productivity, stability, and 708 persistence in a herring metapopulation model. ICES Journal of Marine Science 66, 709 $1726-1732$.

Segers, F. H. I. D., Dickey-Collas, M. \& Rijnsdorp, A. D. (2007). Prey selection by North Sea herring (Clupea harengus), with special reference to fish eggs. ICES Journal of Marine Science 64, 60-68.

Slotte, A. (1999). Effects of fish length and condition on spawning migration in Norwegian spring spawning herring (Clupea harengus L.). Sarsia 84,111-127. Letters 465, 609-613

Schindler, D.E., Hilborn, R., Chasco, B., Boatright, C.P., Quinn, T.P., Rogers, L.A., \& Webster, M.S. (2010). Population diversity and the portfolio effect in an exploited species. Nature

Slotte, A., \& Fiksen, Ø. (2000). State-dependent spawning migration in Norwegian spring-spawning herring. Journal of Fish Biology 56, 138-162.

Toresen, R. (1990). Long term changes in growth on Norwegian springspawning herring. Journal du Conseil International pour l'Exploration de la Mer 47, 48-56. 
723 TABLE 1. Parameter estimates for the reduced von Bertalanffy model. Values in parentheses denote $72495 \%$ confidence intervals.

725

\begin{tabular}{llll}
\hline Parameter & Area & Estimate & \\
\hline $\mathrm{K}$ & All & $0.380(0.279,0.481)$ & 726 \\
$t_{0}$ & All & $-1.94(-2.57,-1.31)$ & 727 \\
$L_{\infty, \text { autumn }}$ & North Sea & $29.7(28.3,31.0)$ & 728 \\
$L_{\infty, \text { autumn }}$ & Skagerrak & $29.4(28.1,30.6)$ & 729 \\
$L_{\infty, \text { autumn }}$ & Kattegat & $26.5(25.2,27.7)$ & \\
$L_{\infty, \text { spring }}$ & North Sea & $28.6(27.4,29.9)$ & 730 \\
$L_{\infty, \text { spring }}$ & Skagerrak & $28.3(27.1,29.5)$ & 731 \\
$L_{\infty, \text { spring }}$ & Kattegat & $25.4(24.3,26.5)$ & 732 \\
& & & \\
\hline
\end{tabular}

733

734 
735 TABLE 2. Average condition of autumn and spring spawners by area. Values in parentheses denote 736 standard error of the estimate. Units are $10^{-3} \mathrm{~g}^{*} \mathrm{~cm}^{-3.26}$

\begin{tabular}{lll}
\hline Area & Autumn spawners & Spring spawners \\
\hline North Sea & $3.70(0.03)$ & $3.58(0.03)$ \\
Skagerrak & $3.73(0.02)$ & $3.52(0.02)$ \\
Kattegat & $3.45(0.04)$ & $3.19(0.02)$ \\
\hline
\end{tabular}

737 
738 Figure 1. The study area. Straight lines indicate ICES management subdivision areas, shading indicate 739 spawning grounds of the WBSS stock based on literature (Biester, 1979; Otterlind, 1987; Rosenberg 740 and Palmén, 2982) and information from local fishermen. The circle represents the main spawning 741 ground (Greifswalder Bodden; Biester, 1979)

742 Figure 2. The proportion of spring spawners by weight in abundance by year and statistical rectangle 743 (grayscale colours) as well as total abundance weight by statistical rectangle and year (bubbles, areas 744 are proportional to total catch weight but rescaled for each year, hence only within year comparisons 745 are possible).

746 Figure 3. Biomass of autumn (top) and spring (bottom) spawners per rectangle across years in the 747 North Sea (black symbols, black line), Skagerrak (grey symbols, grey line) and Kattegat (open 748 symbols, broken line). Lines are regression lines.

749 Figure 4. Left: annual centre of gravity for the autumn spawners (circles with grey thin lines) and 750 spring spawners (circles med black thick lines) size and numbers within circles indicate year as in 751 20xx. Right: average centre of gravity for age classes 1-5 wr, autumn spawners (circles with grey thin 752 lines) and spring spawners (circles med black thick lines) size and numbers within circles indicate age 753 (wr).

754 Figure 5. Ln(Catch in numbers) at age of autumn (left) and spring (right) spawners in the North Sea 755 (solid triangles, solid line), Skagerrak (open diamonds, dotted line) and Kattegat (open squares, dash 756 line). Lines are regression lines. 
757 Figure 6. Predicted length at age for each area and type from the reduced von Bertalanffy model. Left:

758 Autumn spawners, Right: spring spawners. Black: North Sea and Skagerrak, grey: Kattegat. Solid line 759 denotes predicted length, hatched lines the $95 \%$ confidence interval around the prediction.

760 Figure 7. Residuals from the final von Bertalaffy model by year (growth anomalies). Autum spawners 761 (open symbols, hatched line) and spring spawners (closed symbols, solid line) in the North Sea (top 762 left), Skagerrak (top right) and Kattegat (bottom left).

763 Figure 8: Condition (C) of spring spawners vs condition of autumn spawners, by ICES rectangle, year 764 and age. Increasing size of bubbles indicates increasing age from $1 \mathrm{wr}$ to $5 \mathrm{wr}$. 


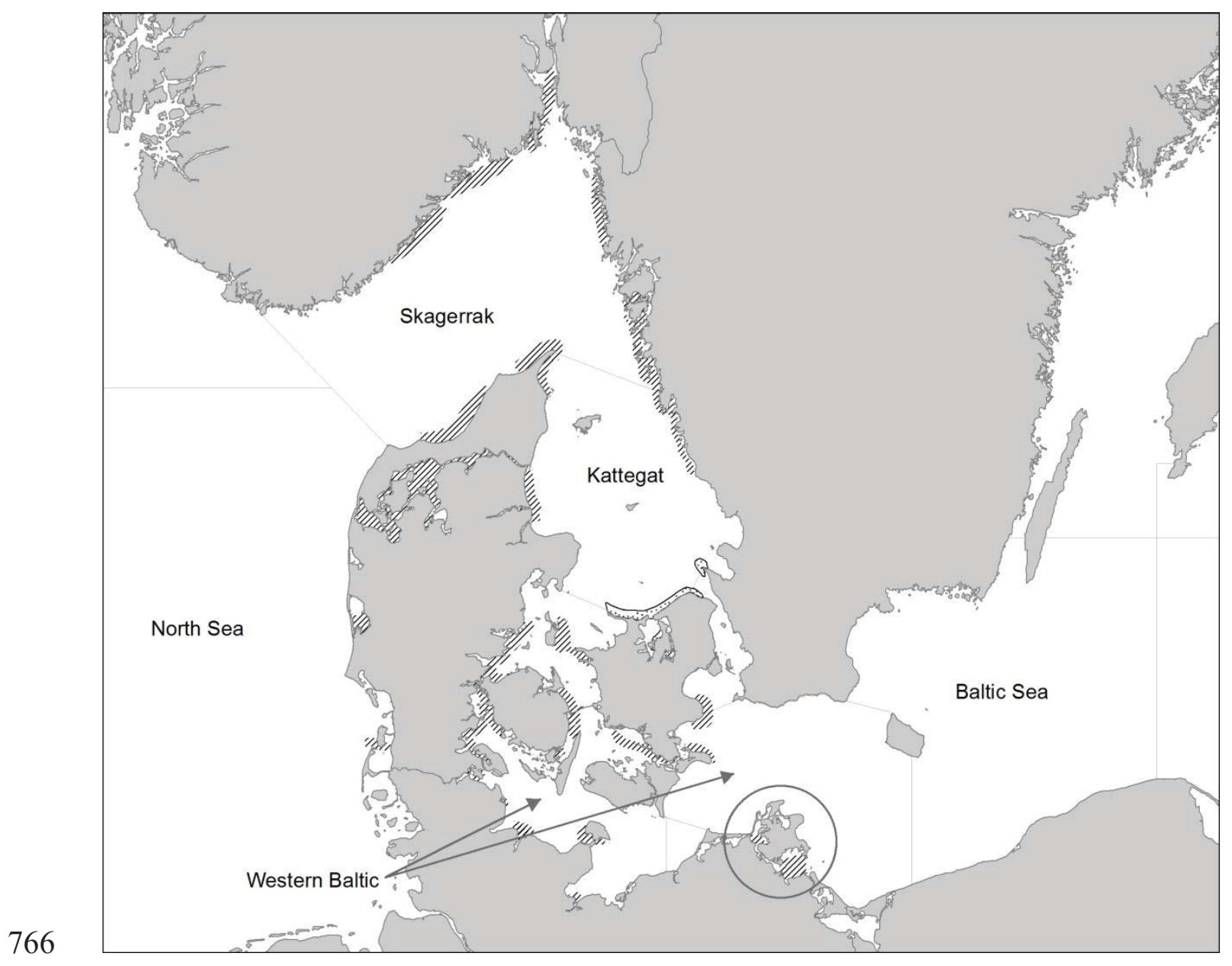

767 Figure 1. 

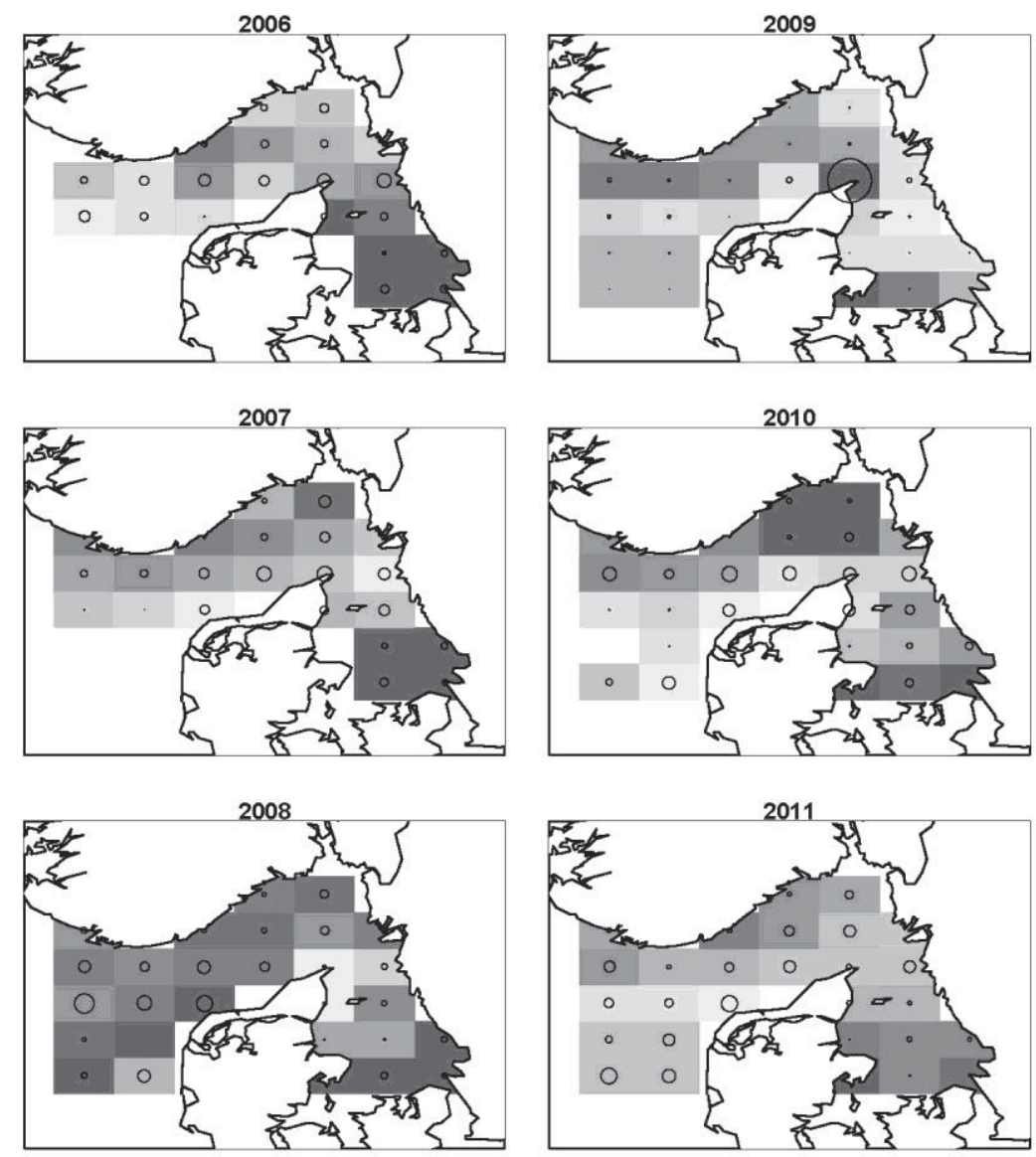

768

769 Figure 2. 


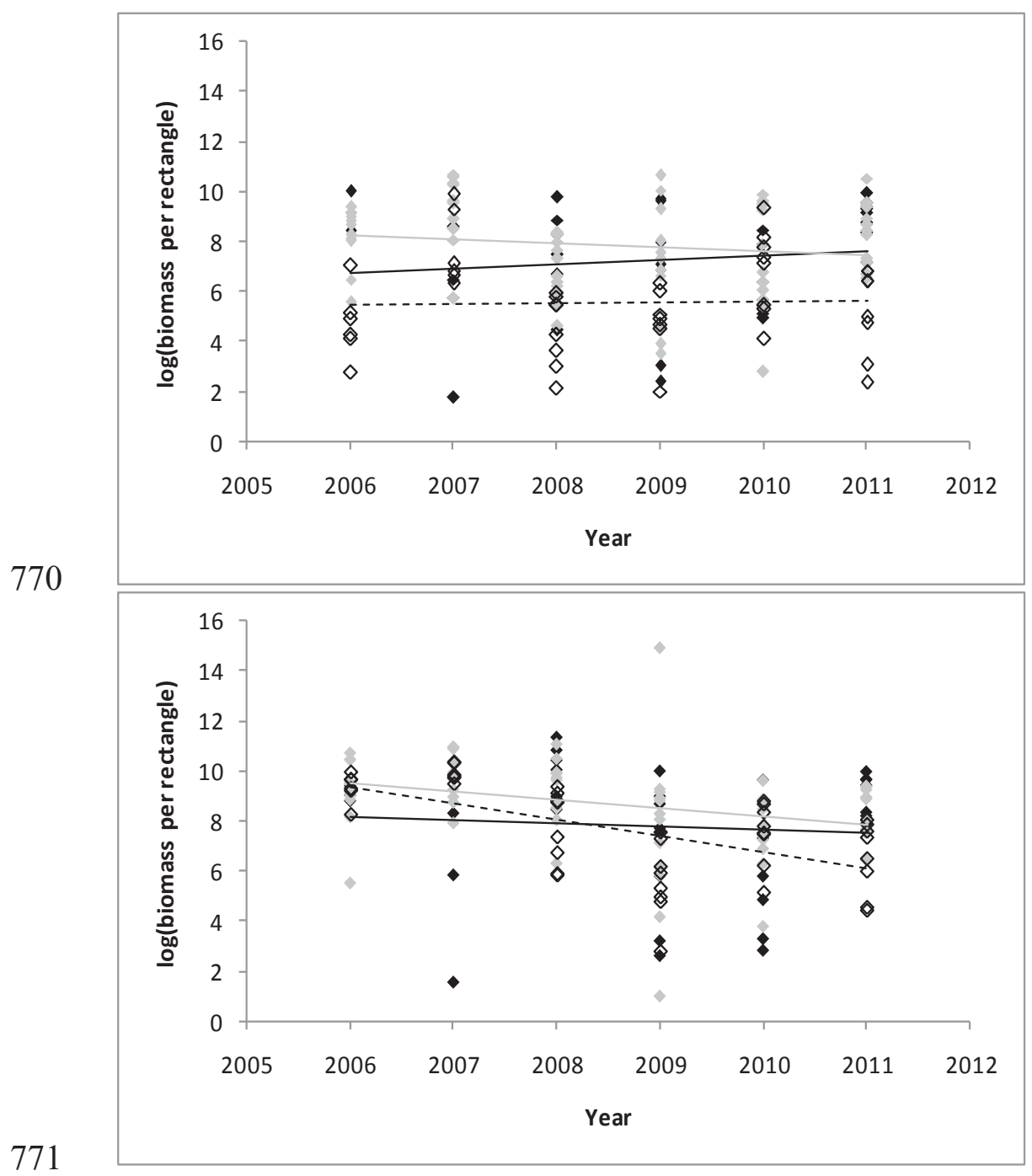

772 Figure 3. 

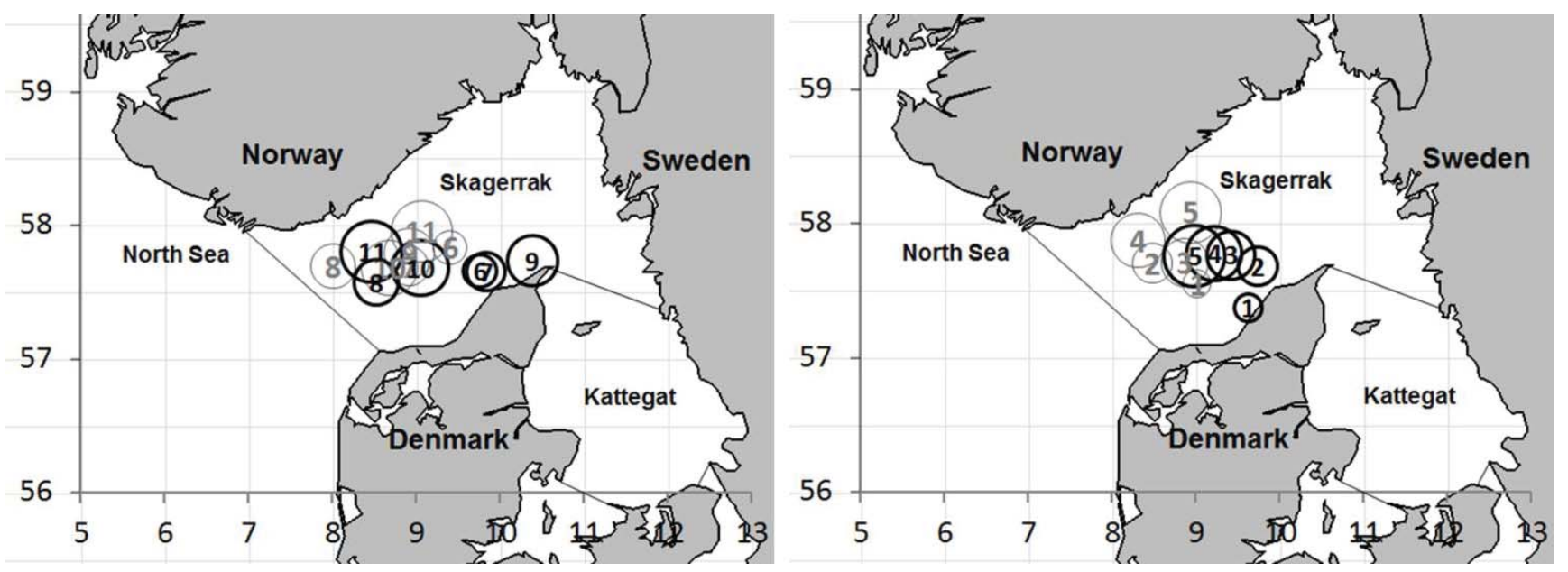

774 Figure 4. 

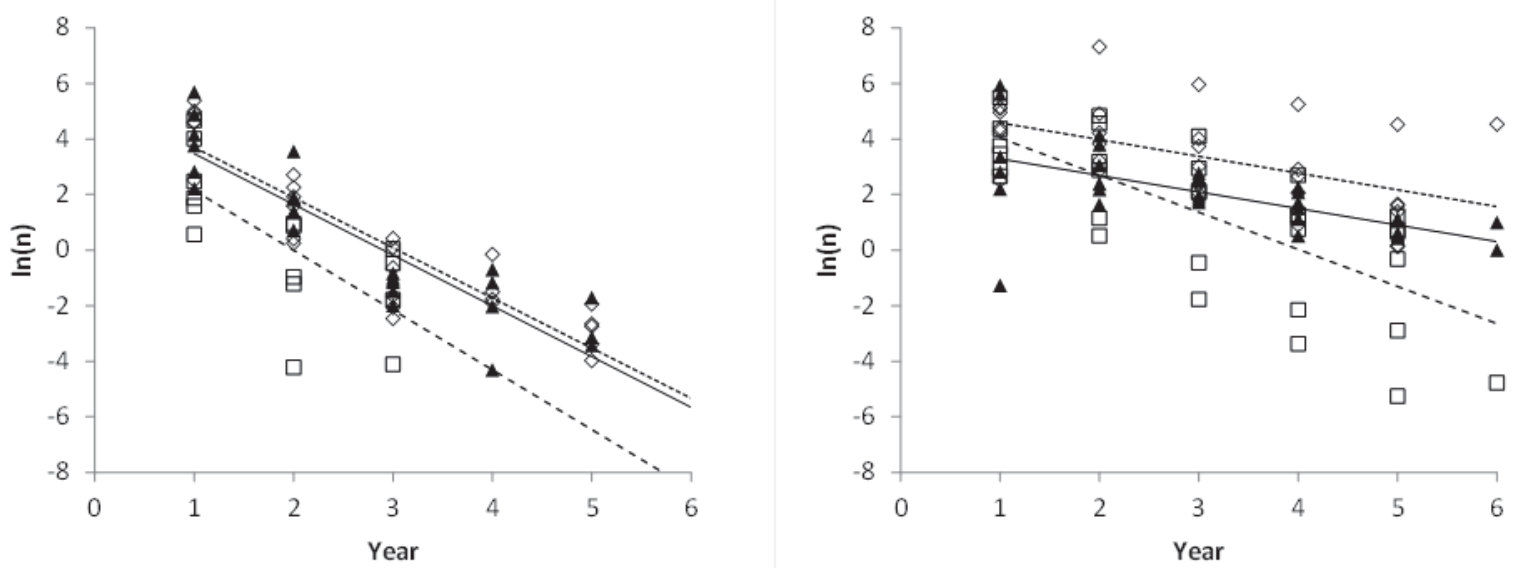

776 Figure 5. 

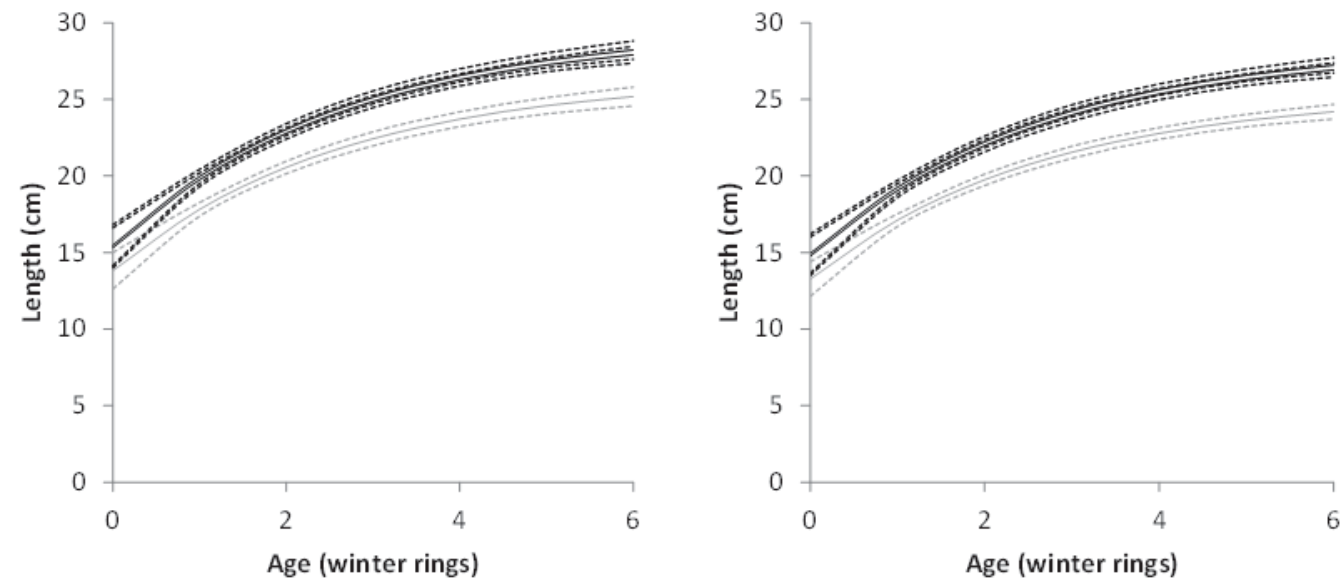

778 Figure 6. 


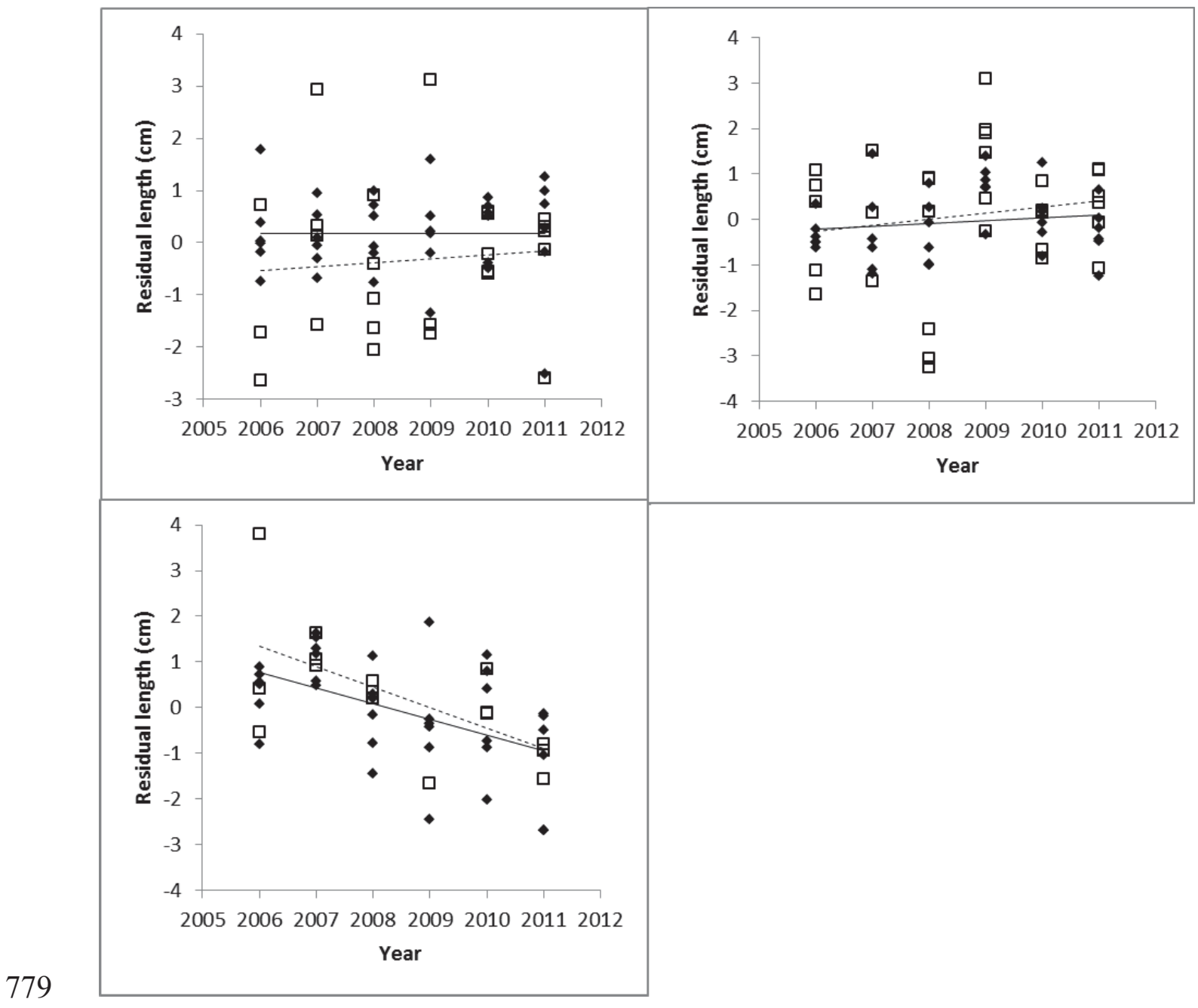

$780 \quad$ Figure 7. 


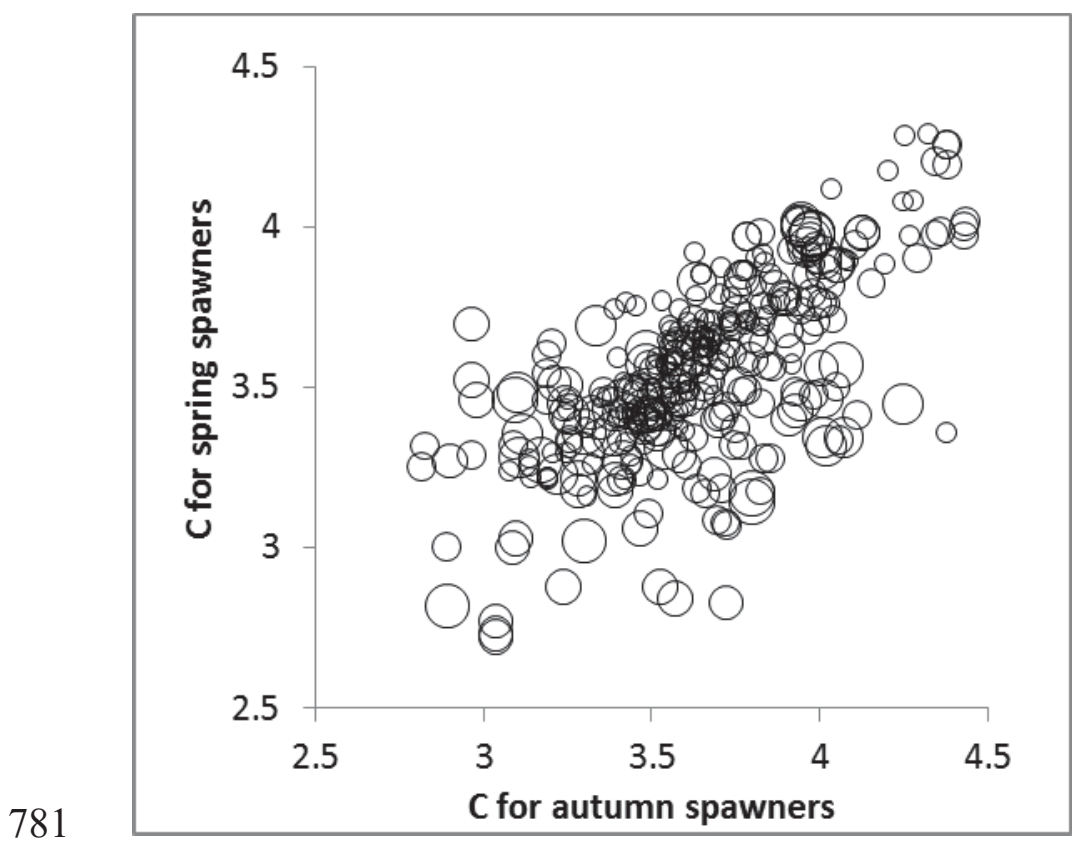

782 Figure 8. 